\title{
Analyzing the Spatial Heterogeneity of the Built Environment and Its Impact on the Urban Thermal Environment-Case Study of Downtown Shanghai
}

\author{
Jiejie Han ${ }^{1,2, *}$, Xi Zhao ${ }^{1}\left(\mathbb{D}\right.$, Hao Zhang ${ }^{1, *}$ and Yu Liu ${ }^{1,3}$ \\ 1 Laboratory for Applied Earth Observation and Spatial Analysis, Department of Environmental Science and \\ Engineering, Jiangwan Campus, Fudan University, Shanghai 200438, China; \\ 19210740064@fudan.edu.cn (X.Z.); liuyu1982@henu.edu.cn (Y.L.) \\ 2 Guangzhou Urban Planning \& Design Survey Research Institute, Guangzhou 510030, China \\ 3 School of Civil Engineering and Architecture, Henan University, Kaifeng 475003, China \\ * Correspondence: fudan_jiejiehan@163.com (J.H.); zhokzhok@163.com (H.Z.)
}

\section{check for} updates

Citation: Han, J.; Zhao, X.; Zhang, H.; Liu, Y. Analyzing the Spatial Heterogeneity of the Built Environment and Its Impact on the Urban Thermal Environment-Case Study of Downtown Shanghai. Sustainability 2021, 13, 11302. https:/ / doi.org/10.3390/su132011302

Academic Editors: Baojie He, Ayyoob Sharifi, Chi Feng and Jun Yang

Received: 15 August 2021

Accepted: 11 October 2021

Published: 13 October 2021

Publisher's Note: MDPI stays neutral with regard to jurisdictional claims in published maps and institutional affiliations.

Copyright: (c) 2021 by the authors. Licensee MDPI, Basel, Switzerland. This article is an open access article distributed under the terms and conditions of the Creative Commons Attribution (CC BY) license (https:// creativecommons.org/licenses/by/ $4.0 /)$.

\begin{abstract}
Ongoing urban expansion has accelerated the explosive growth of urban populations and has led to a dramatic increase in the impervious surface area within urban areas. This, in turn, has exacerbated the surface heat island effect within cities. However, the importance of the surface heat island effect within urban areas, scilicet the intra-SUHI effect, has attracted less concern. The aim of this study was to quantitatively explore the relationship between the spatial heterogeneity of a built environment and the intra-urban surface heat island (intra-SUHI) effect using the thermally sharpened land surface temperature (LST) and high-resolution land-use classification products. The results show that at the land parcel scale, the parcel-based relative intensity of intra-SUHI should be attributed to the land parcels featured with differential land developmental intensity. Furthermore, the partial least squares regression (PLSR) modeling quantified the relative importance of the spatial heterogeneity indices of the built environment that exhibit a negative contribution to decreasing the parcel-based intra-SUHI effect or a positive contribution to increasing the intra-SUHI effect. Finally, based on the findings of this study, some practical countermeasures towards mitigating the adverse intra-SUHI effect and improving urban climatic adaption are discussed.
\end{abstract}

Keywords: built-up environment; spatial heterogeneity; urban thermal environment; blue-green space; land use pattern

\section{Introduction}

Since the era of the industrial revolution, driven by capital flows and labor transfers, urban agglomerations and metropolitan areas have become the preferred destinations for urban-rural and cross-border migrants worldwide [1-3]. At present, global urban areas house more than $50 \%$ of the total population and $70-90 \%$ of all economic activities [4], resulting in unprecedented urban expansion and explosive growth of urban populations. The United Nations Department of Economic and Social Affairs has reported that about $55 \%$ of the global population lives in urban areas. By 2050, global urban residents will increase by 2.5 billion, of which 255 million will be in China, such that the urban population will account for $68 \%$ of the country's total population [5].

During urban expansion, impervious surfaces, such as buildings, roads, squares, bridges, and parking lots, dominate the land-use structure of the built environment. They consequently occupy and replace the area proportion of the pre-development landscapes (e.g., water bodies and vegetation) [6]. The intensive human activities in cities lead to severe ecological degradation [7], which has the consequence of artificial modification of the urban climate; in particular, the urban heat island (UHI) effect and its influences on human health have been of wide concern. To restore the urban natural environment and 
improve urban resilience, artificial blue and green space (BGS), including water bodies, vegetation, and recreational landscapes, can be created and managed in order to deliver critical ecosystem services (e.g., air purification and climate modification) within cities [8-10]. Unfortunately, in most cases, impervious surfaces dominate the urban built environment's land-use structure and landscape pattern. Intensive urban land development usually alters the surface thermal energy radiation, biological characteristics, and hydrological cycle, resulting in changes in the absorption and emission of solar radiation and the surface heat flux [11-13]. Meanwhile, due to its relatively small area proportion within cities, the BGS that promotes local cooling effects is insufficient to offset the overwhelming heat emissions from the impervious surfaces, which heat the lowest layer of the air [14]. Such surface-to-air heating processes have been proven to profoundly impact the urban thermal environment [15-17]; for instance, artificial modification of the urban climate is closely related to the UHI effect, as measured in terms of air temperature (AT) and land surface temperature (LST).

To date, existing studies on the urban thermal environment have mainly focused on the UHI effect, including the boundary layer urban heat island (BLUHI) and canopy urban heat island (CUHI), characterized by AT, as well as the surface urban heat island (SUHI) effect, characterized by LST. The AT can generally be easily measured and used for assessing human thermal comfort, but the sparsity of weather stations within cities and in the urban fringe makes it difficult to characterize the spatial variation of AT, BLUHI, and CUHI in the study area. In contrast, satellite- or air-borne thermal remote sensing platforms, with sizable spatial cover, can provide alternative approaches for monitoring urban climates.

Since the 1970s, spaceborne thermal remote sensing technology has become a practical approach for monitoring regional and local SUHI effects. Previous studies on the multi-scale SUHI effect using spaceborne thermal infrared (TIR) data have produced fruitful results, ranging from low-resolution $(\sim \mathrm{km})$ sensors, such as the Geostationary Operational Environmental Satellite (GOES), the Advanced Very High-Resolution Radiometer (AVHRR), and the Moderate-Resolution Imaging Spectroradiometer (MODIS), to high-resolution (60-120 m) sensors, such as Landsat 5 (Theme Mapper, TM), Landsat 7 (Enhanced Theme Mapper Plus, ETM+), Landsat 8 Operational Land Imager/Thermal Infrared Sensor (OLI/TIRS), and the Advanced Spaceborne Thermal Emission Reflection radiometer (ASTER) [18-20]. At present, given that most urban residents live in intensively developed land lacking green infrastructure, few studies have been carried out on the intra-SUHI effect, which indicates the SUHI effect within urban functioning zones (UFZs) and is closely related to human health and urban climate adaptation. In the context of urban settings characterized by complex land-use structure and landscape configuration, the formation of the intra-SUHI effect largely depends on the fine-scale land developmental features (e.g., land-use types, floor area ratio, building distances and heights, and landscape patterns of specific land parcels) [21,22]. It should be noted that, for these above-mentioned spaceborne TIR sensors, due to the problem of mixing pixels of land surfaces, they are still too coarse to generate detailed information regarding the LST and heat flux and, thus, it is impossible to depict the fine-scale pattern of the urban thermal environment when using such data. In contrast, the airborne high-resolution TIR imaging systems, such as NASA's advanced thermal infrared and land application sensor (ATLAS) and unmanned aerial vehicle (UAV)-borne TIR cameras, can effectively detect the fine-scale thermal effect of urban settings. However, the apparent shortcomings of ATLAS (e.g., fixed navigation routes and low cost-effectiveness) and UAV systems (e.g., flexible navigation routes but short flying durations) limit their applicability in the practice of detecting the variations in the urban thermal environment. Alternatively, recent studies have attempted to combine thermally sharpened satellite-retrieved data with commercial high-resolution optical images in order to provide a practical approach for evaluating the intra-SUHI effect $[23,24]$. Such an approach can provide a better understanding of the relationship between the spatial heterogeneity of the built environment and the urban thermal environment, considering 
that the recent literature emphasizing such relationships is relatively scarce. Moreover, the robustness and applicability of such approaches in practice need further testing in a variety of case studies.

In this study, Shanghai-one of the fast-growing megacities suffering from extreme summertime heat events-was taken as a case study. Our research goals were (1) to quantitatively analyze the spatial heterogeneity of the built environment and its impact on the summertime intra-SUHI effect within the city, and (2), based on the findings of this study, to provide the operational choices for decision making towards enhancing urban planning practices, mitigating the intra-SUHI effect, and improving urban climate adaption.

\section{Study Area}

Shanghai is located between latitudes $30^{\circ} 40^{\prime} \mathrm{N}-31^{\circ} 53^{\prime} \mathrm{N}$ and longitudes $120^{\circ} 52^{\prime}$ E- $122^{\circ} 12^{\prime} \mathrm{E}$, in the front of the alluvial plain of the Yangtze River Delta (see Figure 1). The whole city is low-lying and flat, dominated by plains (with an area of $93.91 \%$ ) and an average altitude of $2.19 \mathrm{~m}$. Shanghai is located in the north sub-tropical monsoon climate zone, with abundant sunshine, abundant rain, and four obvious seasons. Local vegetation types are dominated by evergreen broad-leaved forest and evergreen deciduous broad-leaved mixed forest [25]. At present, the wetland stock is 464,600 hectares, and the forest coverage rate of the whole city reaches $17.6 \%$. In this study, four typical urban functioning zones (UFZs), which represent the socio-economic features and urban land-use patterns within downtown Shanghai (Table 1), were used to investigate the relationship between the urban built environment and intra-SUHI effect.

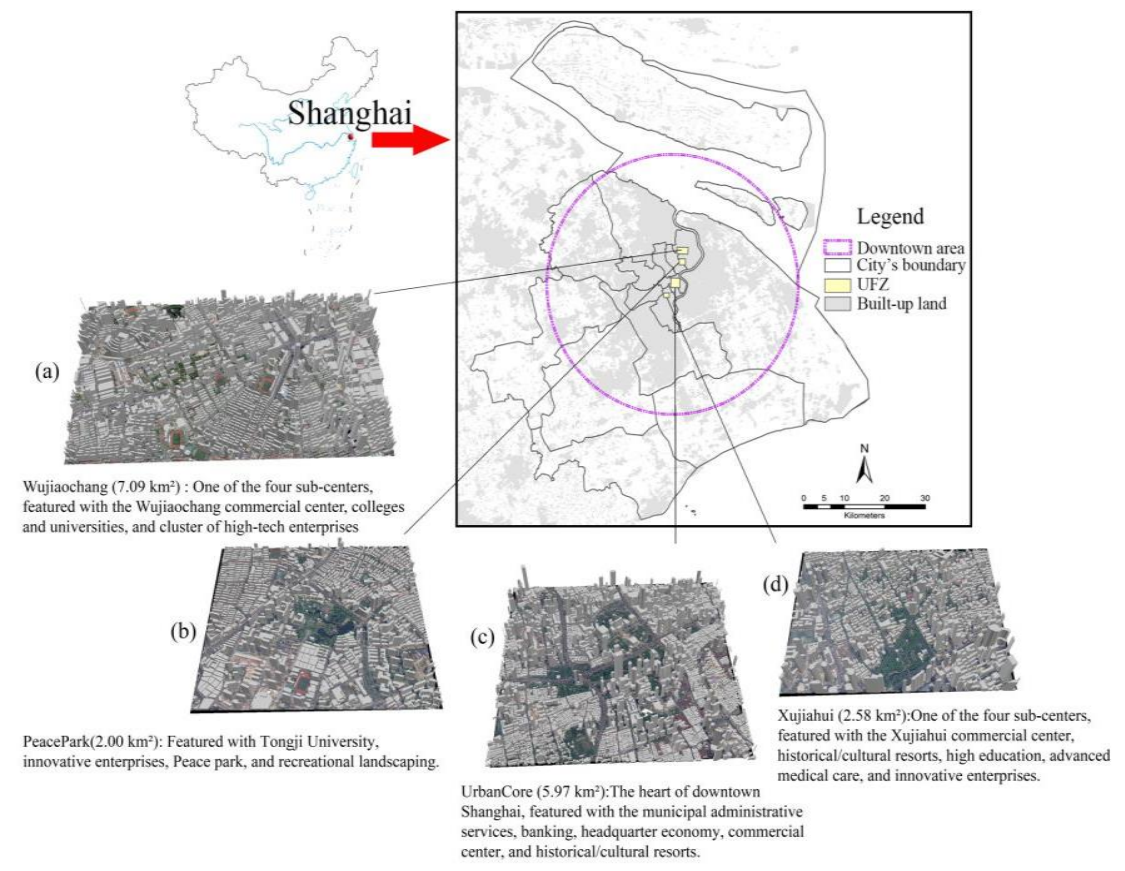

Figure 1. Location of the study area and four UFZs.

Table 1. Description of four UFZs within downtown Shanghai.

\begin{tabular}{|c|c|c|}
\hline UFZ & Area $\left(\mathrm{km}^{2}\right)$ & Description \\
\hline Wujiaochang & 7.09 & $\begin{array}{c}\text { This UFZ includes a shopping center, university campus, research and development institutions, } \\
\text { innovative enterprises, high-tech parks, and residential areas. }\end{array}$ \\
\hline Peace Park & 2.00 & $\begin{array}{l}\text { This UFZ includes parks and recreational landscapes, a university campus, research and } \\
\text { development institutions, innovative enterprises, and residential areas. }\end{array}$ \\
\hline Urban Core & 5.97 & $\begin{array}{c}\text { This UFZ includes parks and recreational landscapes, the municipal administration, central } \\
\text { business district, and residential areas. }\end{array}$ \\
\hline Xujiahui & 2.58 & $\begin{array}{l}\text { This UFZ includes parks, a commercial center, historical and cultural relics, higher education } \\
\text { institutes, a health care center, high-tech enterprises, and residential areas. }\end{array}$ \\
\hline
\end{tabular}




\section{Materials and Methods}

\subsection{Materials}

Landsat 8 OLI/TIRS (Level 1T) and Quickbird imagery were used as the major data sets. Excluding the cloud contaminations, two cloud-free Landsat 8 OLI/TIRS images (path/row: 118/038, cloud cover $<10 \%$ ) acquired during typical summer days (dated 13 August 2013 and 3 August 2015) were used for the retrieval of the LST and further exploration of the pattern of the urban thermal environment. Quickbird commercial highresolution imagery covering the four UFZs was used to classify the fine-scale land-use structure. The auxiliary data sets included a commercial vector map data of Shanghai city (roads, buildings, land-uses, and so on) and an aerial remote sensing atlas of the Shanghai central area. A standard digital map of Shanghai downtown (Beijing Digital Space Technology Co., LTD, 2015, Beijing, China), an aerial atlas of Shanghai (Shanghai Academy of Surveying and Mapping 2015, Shanghai, China), Google Earth, and Baidu Map were used as further auxiliary data sets.

\subsection{Methods}

\subsubsection{Land-Use Classification}

To better depict the fine-scale land-use characteristics from the Quickbird highresolution imagery, the object-oriented classification (OOC) method, which has higher classification accuracy than regular methods, such as spectral feature extraction and classification and regression trees (CART) [26], was used for land classification within the four UFZs.

For the Quickbird high-resolution imagery covering the four UFZs, classification with the OOC method was performed with the use of PIE-Basic ${ }^{\circledR}$ (version 6.0) software by PIESAT International Information Technology Limited. The overall accuracy of classification was $80.03 \%$, and the accuracy of the post-classification was determined to be $93.01 \%$ with a manual check using Google Earth and Baidu Map layers, as well as a field survey. The validated land-use classification product and its classification scheme are shown in Figure A1 and Table A1, respectively.

In this study, considering the simplicity, representability, and availability of the data sets, the spatial heterogeneity of the built environment was measured using the two- and three-dimensional indices of urban morphology and land surfaces.

Table 2 lists several heterogeneity indices that may positively or negatively contribute to the urban thermal environment (for details, see Table A2). According to the National Standard for Urban Residential Planning and Design of China (GB50180-2018) [27], building heights, distances between buildings, and the SVF were calculated from data collected through in situ measurements. The land surfaces, including the impervious surfaces and BGS, were extracted from the land-use classification maps. Specifically, for BGS, the parcelbased land-use information was used to calculate the class-level pattern indices-namely, the mean patch size (MPS), the number of patches (NP), the largest patch index (LPI), and the SPLIT index-using Fragstats 4.2.1 software [28]. The three-dimensional green volume (3DGV) of the BGS, which refers to the total volume of vegetation with stratified layers, was estimated using several empirical models, ground measurements, and aerial photogrammetry [29].

\subsubsection{Generation of Thermally Sharpened LST and Cross-Validation}

The process for generating the thermally sharpened LST consisted of four steps. First, the 10 gray value thermal band Landsat 8 Level $1 \mathrm{~T}$ data was converted to the top of atmosphere (TOA) radiance using the rescaling factors in the MTL file [30].

Secondly, co-Kriging interpolation was employed to generate the high-resolution TOA radiance by combining the Quickbird high-resolution land-use classification products and the raw TOA radiance [31]. Given the different resolutions of these two data sets, the high-resolution land-use classification products were resampled with multiple resolutions (1-9 $\mathrm{m})$ and set as base maps to overlap and delimit the raw TOA radiance layer. We 
assumed that the same or similar surfaces would have the same or similar radiance values. Then, for each scene of the TOA radiance layer, tedious sampling of random points (ranging between 300 and 6000 points per $\mathrm{km}^{2}$ ) was carried out in order to generate the co-Kriging interpolation results. By comparing the pairwise bias curve between the raw and interpolated TOA radiance values, we found that the threshold of 3000 points was reasonable, as the curve flattened and was nearly unchanged when the number of points was over 3000 [32]. Subsequently, the interpolated TOA radiance layer was resampled to multiple resolutions (1-9 m).

Table 2. Statistical description of indices used in this study.

\begin{tabular}{|c|c|c|c|c|c|c|c|}
\hline Classification & Metrics & Abbr. & Unit & Range & Median & Mean & Sd \\
\hline \multirow{4}{*}{$\begin{array}{c}\text { Urban } \\
\text { morphology }\end{array}$} & Building height & Height & $\mathrm{m}$ & $2.7-165.0$ & 11.00 & 16.470 & 15.21 \\
\hline & Building spacing & Distance & $\mathrm{m}$ & $4.3-107.1$ & 19.82 & 23.030 & 14.72 \\
\hline & Sky view factor & SVF & $\%$ & $2.48-26.38$ & 13.19 & 12.053 & 6.0 \\
\hline & Area of impervious surface & ImperSurf & ha & $0.47-24.96$ & 5.08 & 6.016 & 4.16 \\
\hline \multirow{6}{*}{ Land surface } & Area of blue-green space & BGS & ha & $0.13-15.89$ & 1.66 & 2.393 & 2.38 \\
\hline & Mean patch size & MPS & ha & $0.00-0.44$ & 0.01 & 0.030 & 0.05 \\
\hline & Largest patch index & LPI & - & $8.61-99.25$ & 34.40 & 40.210 & 22.800 \\
\hline & Number of patches & NP & - & $8.00-840.00$ & 96.500 & 124.340 & 110.870 \\
\hline & SPLIT & SPLIT & - & $1.015-37.299$ & 6.005 & 7.383 & 5.938 \\
\hline & 3D green volume & 3DGV & $\mathrm{m}^{3}$ & $\begin{array}{c}8001.702- \\
834,316.313\end{array}$ & $92,085.870$ & $133,118.807$ & $135,579.551$ \\
\hline
\end{tabular}

Third, based on the multiple-resolution land-use maps, a surface emissivity correction for the land surfaces was performed according to empirical studies and laboratory testing [33,34]. The multiple-resolution interpolated TOA radiance and corrected surface emissivity layers were used to retrieve the thermally sharpened LST using the Range Transfer Equation (RTE) [35], which requires atmospheric correction for the thermal band [36].

Finally, cross-validation of the thermally sharpened LST products was performed by comparing the pixel-based root-mean-square error (RMSE) between the target LSTs (sharpened) and referencing LSTs [37]. To do so, all the thermally sharpened LST products were resampled to the same resolution as the unsharpened LST products $(30 \mathrm{~m})$. Then, by overlapping the $30 \mathrm{~m}$ unsharpened LST products and the LST products resampled from the sharpened products, the pixel-to-pixel 10-fold RMSEs were used for cross-validation of the thermally sharpened LST products. As shown in Figure A3, there were no significant differences in the RMSEs of the LST products (resampled from the 1-9 m sharpened LST products) and the original $30 \mathrm{~m}$ LST products; however, as they exhibited the best visual quality and the lowest RMSE, the $1 \mathrm{~m}$ resolution sharpened LST products were used for further analysis.

\subsubsection{Calculation of Intra-SUHII}

Rather than using the generalized concept of the UHI effect as measured by the LST difference between urban and rural areas, the intra-SUHI intensity in this study is defined as the LST difference between the impervious surfaces and the BGS (vegetated land and water bodies) in a given land parcel. The parcel-based intra-SUHII is calculated as follows [38]:

$$
\text { Intra }-\mathrm{SUHII}=\mathrm{LST}_{\mathrm{IS}}-\mathrm{LST}_{\mathrm{BGS}}
$$

where the unit of intra-SUHII is Kelvin (K), $\mathrm{LST}_{\mathrm{IS}}$ represents the average LST of the

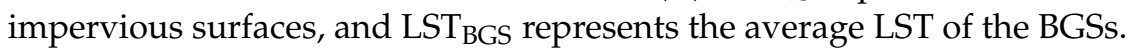

At the land parcel level, according to the statistical description and analysis method, the intra-SUHIIs were divided into six levels, according to the percentile threshold on the cumulative probability curve of their normal distribution, as follows: Level 1-very low ( $\leq 5 \%)$; Level 2-low (5-25\%); Level 3-low to slightly high (25-50\%); Level 4-mediumhigh (50-75\%); Level 5-high (75-95\%); Level 6-very high ( $\geq 95 \%$ ). 


\subsubsection{Statistical Analysis}

This section mainly describes hierarchical cluster analysis (HCA) and partial least squares regression (PLSR) modeling. The former was used for the overall characterization of the land parcel clusters with differential land developmental intensity, while the latter was used for exploring the relationship between the intra-SUHII and multiple independent variables, particularly in the case of multi-collinearity. Essential data analysis was performed, including a normality test, outlier detection, Box-Cox transformation for skewed data, and Pearson's correlation. With the indices described in Table 2, HCA was performed using the Euclidean distance method. Seven typical land parcel clusters representing differential land developmental intensity were obtained (see Table A3).

The statistically significant correlation coefficients (see Table 4) revealed the existence of multi-collinearity between the independent variables. According to the result of Pearson correlation analysis, as there are many possible forms of PLSR models that involve the independent variables, it is time-consuming to establish the PLSR models. To avoid overfitting and determine a reasonable model, the leave-one-out (LOO) method was adopted, setting $90 \%$ of the randomly selected data as the training data and the rest as the test data. Finally, the optimal PLSR model, satisfying the highest determination coefficient $\left(\mathrm{R}^{2}\right)$ and minimum root mean square error (RMSE), was selected. The PLSR model, indicating the relationship between the intra-SUHII and the impervious surfaces, was written as follows:

$$
\text { Intra-SUHII }=\alpha_{1}+\beta_{1} \cdot X_{1}+\beta_{2} \cdot X_{2}+\beta_{3} \cdot X_{3}+\beta_{4} \cdot X_{4}+\beta_{5} \cdot X_{5}+\varepsilon_{1}
$$

where $\alpha_{1}$ is the intercept/constant item, $\beta_{1}-\beta_{5}$ are the partial coefficients; $X_{1}-X_{5}$ are the height, distance, SVF, ImperSurf, and parcel area, respectively; $\varepsilon_{1}$ is the error term.

Similarly, the PLSR model, indicating the relationship between the intra-SUHII and the BGS, was written as follows:

$$
\text { Intra-SUHII }=\alpha_{1}+\beta_{1} \cdot X_{1}+\beta_{2} \cdot X_{2}+\beta_{3} \cdot X_{3}+\beta_{4} \cdot X_{4}+\beta_{5} \cdot X_{5}+\beta_{6} \cdot X_{6}+\beta_{7} \cdot X_{7}+\varepsilon_{1}
$$

where $\alpha_{1}$ is the intercept/constant item, $\beta_{1}-\beta_{7}$ are the partial coefficients; $X_{1}-X_{7}$ are the $3 \mathrm{DGV}, \mathrm{BGS}, \mathrm{MPS}, \mathrm{NP}, \mathrm{LPI}$, SPLIT, and parcel area, respectively; $\varepsilon_{1}$ is the error term.

In this study, all the essential statistical processes were performed using $R$ statistical software 4.0.3 (developed at Bell Laboratories (formerly AT\&T, now Lucent Technologies, Paris, France) by John Chambers and colleagues), and PLSR modeling was performed using the library 'pls' [39].

\section{Results}

\subsection{Spatial Distribution Characteristics of the Urban Thermal Environment}

Overall, Figure 2 reveals the spatial distribution of the urban thermal environment indicated with parcel-based LSTs and intra-SUHII levels on two summer days of 2013 and 2015, respectively. Figure 2a-h shows the remarkable pixel-based LST difference between the land parcels dominated with impervious surfaces and BGS. Figure $2(\mathrm{a}-1-\mathrm{h}-1)$ shows the variations of the parcel-based intra-SUHII levels, which exhibit the similar spatial patterns shown in Figure 2a-h.

Table 3 shows the statistics of parcel-based LST associated with seven typical land parcel types featured with different land developmental intensities (see Table A3). As shown, Type I and VII parcels exhibited the lowest and second-lowest mean LSTs, followed by Type IV parcels. Apparently, these Type I, IV, and VII parcels, which featured dominant BGS and lower impervious surfaces, exhibited much lower mean LSTs than the other land parcel types. It is noteworthy that Type III, V, and VI parcels exhibited much higher mean LSTs, indicating that the adverse thermal effect is related to higher developmental intensity and lacking BGS. However, for Type V parcels, their temporally highest mean LSTs could be alleviated if newly BGS are created in their later management. 

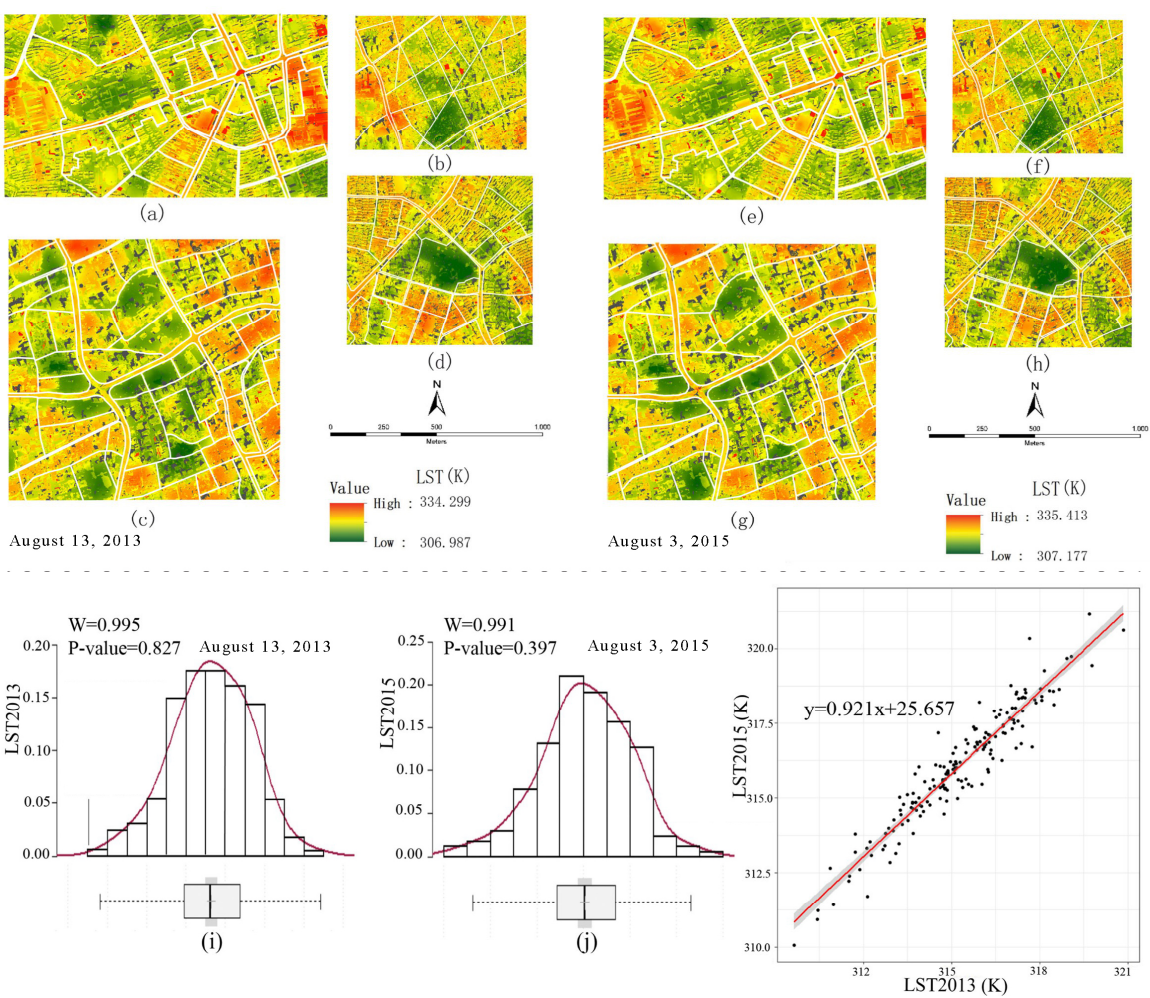

(k)

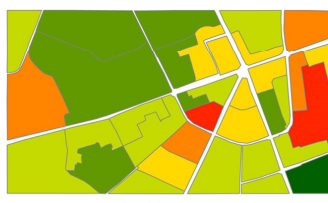

(a-1)

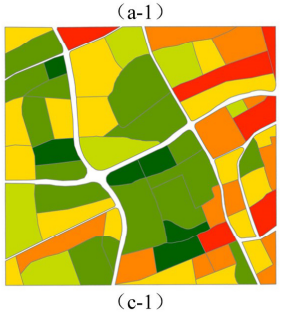

August 13, 2013

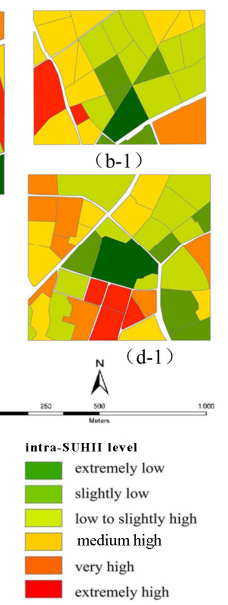

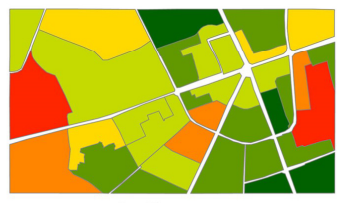

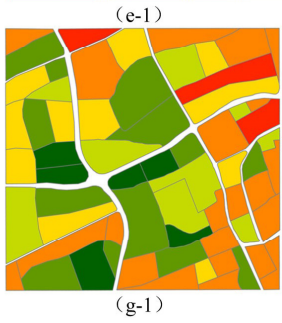

August 3, 2015
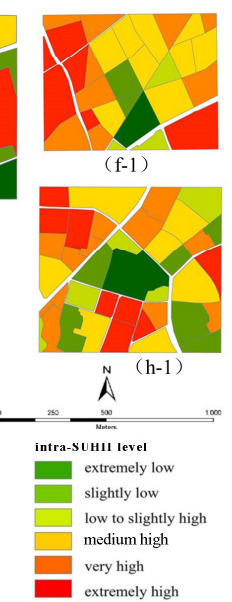

Figure 2. Spatial pattern of pixel-based LSTs and distribution pattern of parcel-based intra-SUHII levels at four UFZs (unit: K).

\subsection{Relationship between the Spatial Heterogeneity of the Built Environment and the Urban} Thermal Environment

Table 4 shows the significant positive and negative correlations between the spatial heterogeneity indices of the built environment, indicating the complicated relationships between the BGS and urban morphological characters. As shown, a competitive land-use structure exists between the ImperSurf and BGS across the land parcels. The significant negative coefficients between the ImperSurf and the BGS, LPI, MPS, and 3DGV indicate that the dominance of the ImperSurf is inclined to decrease the BGS, LPI, MPS, and 3DGV. The significant positive coefficient between the ImperSurf and the SPLIT indicates that the ImperSurf is inclined to increase the SPLIT since the dominance of the ImperSurf usually causes the absence of BGS and, consequently, an uneven pattern of BGS. On the other hand, the significant positive coefficients between the building distances and BGS, LPI, MPS, and 3DGV indicate that, to a certain extent, wider distances between buildings help shape a better BGS landscape configuration since the former provides available space for the 
creation of BGS. Moreover, the significant positive coefficients between the BGS, LPI, MPS, and 3DGV indicate the overall high standard of creation and management of the existing BGS, particularly under the pressure of ecological land scarcity in urban settings.

Table 3. LST statistics of seven characteristic types of land parcels.

\begin{tabular}{ccccc}
\hline Clustered Land Parcel Type & Min LST (K) & Max LST (K) & Mean LST (K) & Range (K) \\
\hline $\begin{array}{c}\text { Type I: Parks and } \\
\text { recreational landscape }\end{array}$ & 307.503 & 319.376 & 312.151 & 11.873 \\
\hline $\begin{array}{c}\text { Type II: Mixture use of } \\
\text { high-density residential and } \\
\text { commercial areas }\end{array}$ & 314.296 & 328.853 & 316.804 & 14.557 \\
\hline $\begin{array}{c}\text { Type III: Poorly-planned } \\
\text { old residential }\end{array}$ & 315.793 & 320.829 & 319.193 & 5.036 \\
\hline $\begin{array}{c}\text { Type IV: Well-planned } \\
\text { modern residential }\end{array}$ & 313.718 & 321.178 & 315.584 & 7.46 \\
\hline $\begin{array}{c}\text { Type V: Mixture of land under } \\
\text { construction and high-density } \\
\text { low-rise (residential) }\end{array}$ & 314.076 & 321.196 & 319.293 & 7.12 \\
\hline $\begin{array}{c}\text { Type VI: Mixture of medium } \\
\text { and high-density residential } \\
\text { and commercial area }\end{array}$ & 316.215 & 321.357 & 318.432 & 5.142 \\
\hline $\begin{array}{c}\text { Type VII: University and } \\
\text { college campus }\end{array}$ & 309.212 & 316.346 & 313.324 & 7.134 \\
\hline
\end{tabular}

Table 4. Pearson correlation coefficients between heterogeneity indices.

\begin{tabular}{|c|c|c|c|c|c|c|c|c|c|c|}
\hline & 3DGV & BGS & NP & LPI & SPLIT & MPS & Height & Distance & ImperSurf & SVF \\
\hline BGS & $0.733^{* *}$ & & & & & & & & & \\
\hline NP & 0.105 & 0.063 & & & & & & & & \\
\hline LPI & $0.311^{* *}$ & $0.442^{* *}$ & $-0.417^{* *}$ & & & & & & & \\
\hline SPLIT & $-0.301^{* *}$ & $-0.498^{* *}$ & $0.435^{* *}$ & $-0.756^{* *}$ & & & & & & \\
\hline MPS & $0.672^{* *}$ & $0.605^{* *}$ & $-0.493^{* *}$ & $0.591^{* *}$ & $-0.617^{* *}$ & & & & & \\
\hline Height & -0.090 & -0.091 & 0.089 & -0.092 & 0.135 & $-0.178^{*}$ & & & & \\
\hline Distance & $0.290^{* *}$ & $0.293^{*}$ & -0.069 & $0.363^{* *}$ & $-0.236^{* *}$ & $0.392^{* *}$ & 0.123 & & & \\
\hline ImperSurf & $-0.692^{* *}$ & $-0.953^{* *}$ & 0.065 & $-0.491^{* *}$ & $0.552^{* *}$ & $-0.662^{* *}$ & 0.100 & $-0.342^{* *}$ & & \\
\hline SVF & $-0.177^{*}$ & -0.123 & $0.156^{*}$ & $-0.151^{*}$ & $0.18^{*}$ & $-0.242^{* *}$ & $0.969^{* *}$ & -0.071 & 0.146 & \\
\hline Parcel-area & $-0.733^{* *}$ & $-0.538^{* *}$ & $0.400^{* *}$ & 0.009 & 0.020 & $-0.402^{* *}$ & -0.069 & 0.110 & $0.631^{* *}$ & -0.101 \\
\hline
\end{tabular}

Note: Except for height, the other indices were Box-Cox transformed. * and ** indicate the significance levels of 0.05 and 0.01 , respectively.

Table 5 quantifies the relationship between the impervious surfaces' two- and threedimensional indices and parcel-based intra-SUHII on two summer days. Herein, considering the independent variables were measured in different units, the standardized regression coefficients (S-Coefs) were used to interpret the results of the PLSR models. As shown, the PLSR models account for approximately $48.7-49.8 \%$ of the variance of parcel-based intra-SUHII in response to the independent variables. The positive and negative S-Coefs indicate their relative importance or strength in determining the variance of parcel-based intra-SUHII. The positive S-Coefs of ImperSurf indicate it exerted a much higher influence on increasing the parcel-based intra-SUHII. When controlling the other independent variables, each standard deviation increase in ImperSurf resulted in a $0.455 \sim 0.480$ standard deviation increase in parcel-based intra-SUHII on two typical summer days. In contrast, the small positive S-Coefs of the parcel area indicate its very weak contribution to the increase in the parcel-based intra-SUHII. The negative S-Coefs of distance, height, and SVF indicate their descending ordinal of relative importance in negatively contributing to the variance of parcel-based intra-SUHII, as each standard deviation increase measured in these indices 
caused $-0.368 \sim-0.360,-0.135 \sim-0.111$, and $-0.066 \sim-0.082$ standard deviation decreases in the parcel-based intra-SUHII, respectively.

Table 5. Coefficients of PLSR models focusing on impervious surfaces.

\begin{tabular}{ccccc}
\hline & \multicolumn{2}{c}{ Intra-SUHII2013 } & \multicolumn{2}{c}{ Intra-SUHII2015 } \\
\cline { 2 - 5 } & Coef & S-Coef & Coef & S-Coef \\
\hline Constant & 7.673 & 0.000 & 6.583 & 0.000 \\
Distance & -3.338 & -0.368 & -3.161 & -0.360 \\
Height & -0.180 & -0.135 & -0.144 & -0.111 \\
SVF & -0.028 & -0.082 & -0.021 & -0.066 \\
ImperSurf & 0.000 & 0.455 & 0.000 & 0.480 \\
Parcel area & 0.128 & 0.042 & 0.216 & 0.072 \\
Variance explained & & $48.7 \%$ & & $49.8 \%$ \\
\hline
\end{tabular}

Note: Coef and S-Coef represent the unstandardized and standardized coefficients, respectively.

Table 6 shows the PLSR models account for approximately 41.7-43.1\% of the variance of parcel-based intra-SUHII in response to the independent variables. The positive S-Coefs of SPLIT, parcel area, and MPS indicate their influence on increasing the parcel-based intra-SUHII. When controlling the other independent variables, each standard deviation increase in the SPLIT and parcel-area resulted in 0.186 0.198 standard deviation increases and 0.079 0.105 standard deviation increases in parcel-based intra-SUHII, respectively. In contrast, the smaller S-Coefs of MPS indicate its very weak importance in increasing the parcel-based intra-SUHII. Meanwhile, the descending sequence of negative S-Coefs of LPI, BGS, NP, and 3DGV indicate their differential relative importance in negatively contributing to the variance of parcel-based intra-SUHII, as each standard deviation increase measured in these indices caused $-0.169 \sim-0.159,-0.142 \sim 0.137,-0.064 \sim-0.028$, and $-0.047 \sim-0.026$ standard deviation decreases in the parcel-based intra-SUHII, respectively.

Table 6. Coefficients of PLSR models focusing on BGS.

\begin{tabular}{ccccc}
\hline & \multicolumn{2}{c}{ Intra-SUHII2013 } & \multicolumn{2}{c}{ Intra-SUHII2015 } \\
\cline { 2 - 5 } & Coef & S-Coef & Coef & S-Coef \\
\hline Constant & 10.028 & 0.000 & 8.738 & 0.000 \\
LPI & -1.288 & -0.159 & -1.323 & -0.169 \\
BGS & -0.374 & -0.137 & -0.375 & -0.142 \\
NP & -0.381 & -0.064 & -0.164 & -0.028 \\
3DGV & -0.098 & -0.047 & -0.053 & -0.026 \\
SPLIT & 1.058 & 0.186 & 1.087 & 0.198 \\
Parcel area & 0.244 & 0.079 & 0.312 & 0.105 \\
MPS & 0.171 & 0.039 & 0.113 & 0.027 \\
Variance explained & & $41.7 \%$ & & $43.1 \%$ \\
\hline
\end{tabular}

Note: Coef and S-Coef represent unstandardized partial regression and standardized partial regression coefficients, respectively.

\section{Discussion}

The findings of this study show that, to an extent, the goal of alleviating the intra-SUHI effect can be achieved via optimizing land parcel design, for instance, by increasing the building distance/spacing and SVF, increasing the area proportion of BGS and 3DGV, and improving the spatial configuration of BGS. Taking the Cui-hu-tian-di (CHTD) modern residence (well planned) and the neighboring old residence (poorly planned) as examples, Figures 3 and 4 show the contrasting intra-SUHI effects between these two land parcels at the Urban Core UFZ. As can be seen, the CHTD modern residence, with higher building spacing (averaged $46 \mathrm{~m}$ ) and higher BGS cover (39\%), exhibits overall lower LSTs (ranging between $307 \mathrm{~K}$ and $318 \mathrm{~K}$, and averaging $309 \mathrm{~K}$ ). Moreover, together with the trees, the higher buildings with wide spacing help create shadow areas and ventilation corridors for cooling. In contrast, the neighboring old residence, with poorly planned building 
spacing (averaging $5 \mathrm{~m}$ ) and lacking BGS, exhibits much higher LSTs (ranging between 309 and $330 \mathrm{~K}$, and averaging $317 \mathrm{~K}$ ). Obviously, for such an old residence, if future urban regeneration is performed with the land parcel design attributes of the CHTD modern residence, then the intra-SUHI effect will be substantially enhanced.

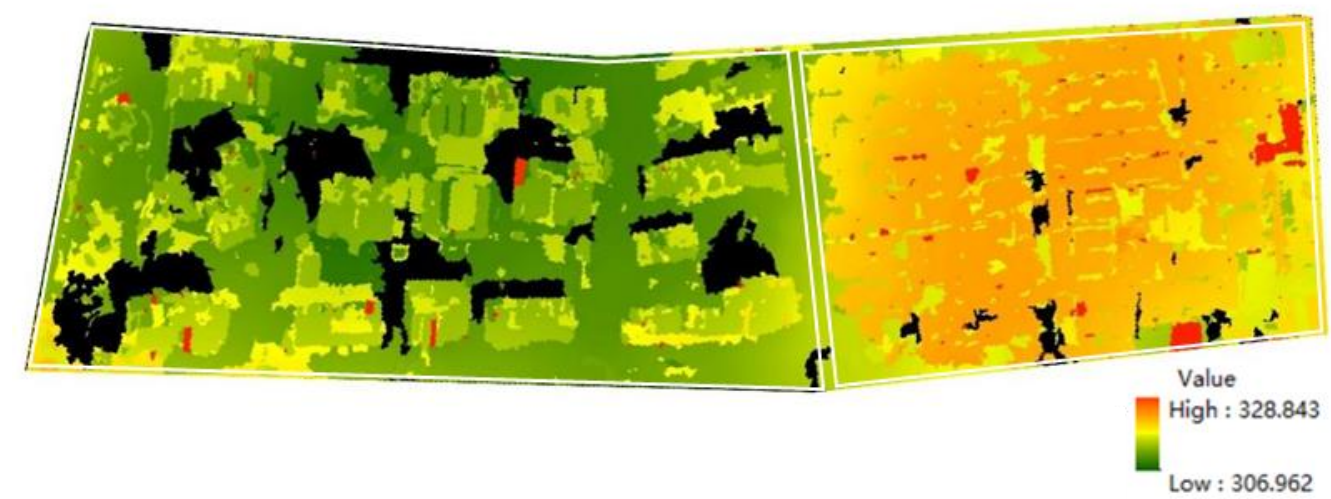

Figure 3. Comparison of fine-scale LSTs of two neighboring land parcels located at the Urban Core UFZ.

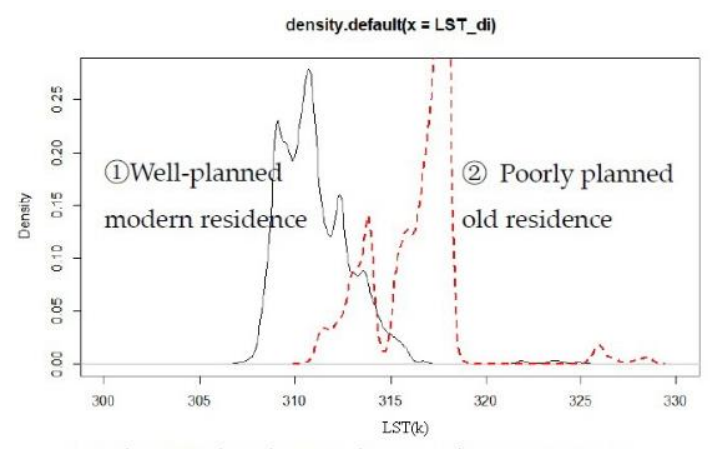

(a) The LST distribution density of two contrasting land parcels

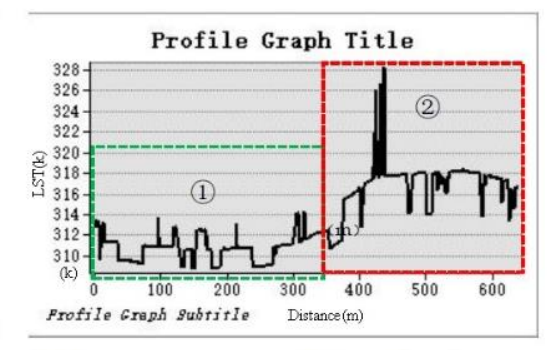

(b) The westing-easting LST profiles drawn from the left end (CHTD modern residence) to the right end (old residence)

Figure 4. Comparison of fine-scale LSTs of two neighboring land parcels.

In the sense of urban resilience and urban planning, our findings exemplify the relative importance of land parcel design attributes in positive or negative contributions to the intra-SUHI effect. However, there are some shortcomings of this study. Firstly, due to the 16-day revisiting interval of the Landsat 8 satellite and cloud contamination [30], the TIRS data captured within the instantaneous field of view (IFOV) could not provide sufficient a time series of thermal images for studying the seasonal variation of the intra-SUHI effect. Secondly, until now, the satellite-borne thermal sensors could not generate the $\sim \mathrm{m}$ resolution data. We used thermally sharpened LSTs, which lack in situ measurements for validation since there are no weather stations or long-term observation sites of the four UFZs in downtown Shanghai [6,37]. Thirdly, the focus of this study was on the possible linkage between solar radiation and the thermal effect of land surfaces in built environments, regardless of the influence of the micro-climatic conditions. Thus, the interpretation power of the PLSR models is somewhat low. Fourthly, the findings of this study ignore the influence of anthropogenic heat emission, considering the complicated relationship that exists between the LST-based intra-SUHI effect and the AT-based UHI effect at a small scale.

Given the above shortcomings, future research should focus on the multi-point distribution of data monitoring and improve the empirical research system. Data assimilation processes, including three-dimensional modeling, computational fluid dynamics (CFD), machine learning methods and other technologies, the long-term in situ observation data, thermal infrared remote sensing data, and numerical simulation results, can provide ensured outputs with cross-validation and improve the accuracy of the prediction modeling. 


\section{Conclusions}

In this study, we quantitatively examined the spatial heterogeneity of the built environment and its impact on the summertime intra-SUHI effect using the high-resolution land-use classification products and thermally sharpened LSTs. The findings are summarized as follows:

1. There are remarkable variations of LSTs and intra-SUHII among seven typical land parcels with different land developmental intensities. Overall, land parcels featured with dominant BGS and lower impervious surfaces, particularly parks and recreational landscapes, a university/college campus with a higher green cover, and well-planned modern residences exhibited much lower mean LSTs than the other land parcel types with dense buildings and lacking BGS.

2. The PLSR models quantitatively revealed the relative importance of the main effect of the urban built environment in determining the variances of the urban thermal environment. The results show that the building distance/spacing, SVF, LPI, and BGS are major negative contributors to decreasing the variance of the parcel-based intraSUHI effect. In contrast, the ImperSurf and SPLIT are major positive contributors to increasing the variance of the parcel-based intra-SUHI effect.

To sum up, based on the findings, this study provides some practical implications towards alleviating the adverse UHI effects via potentially optimizing the land parcel design attributes, particularly focusing on increasing the two- and three-dimensional indices of BGS and reducing the influence of impervious surfaces. Future urban decisionmaking processes of mitigating UHI effects and improving cities' adaption to climate change should sufficiently embody these key points and produce scientifically sound countermeasures.

Author Contributions: H.Z. conceived the central idea and designed the technical framework for this study; J.H., X.Z. and Y.L. conducted the data processing and analysis; J.H. wrote the initial manuscript; H.Z. reviewed and edited the manuscript. All authors have read and agreed to the published version of the manuscript.

Funding: This research received no funding and The APC was covered with MDPI 's discount vouchers (reviewer's token) assigned to H.Z.

Institutional Review Board Statement: Not applicable.

Informed Consent Statement: Not applicable.

Data Availability Statement: The authors thank the Geospatial Data Cloud site, Computer Network Information Center, and the Chinese Academy of Sciences (http:/ / www.gscloud.cn) (accessed on 12 October 2017) for providing the free Landsat TM/OLI images. The authors are indebted to the $\mathrm{R}$ Foundation for Statistical Computing and Beijing Piesat Information Technology Co., Ltd., for free usage of the PIE 6.0 Remote Sensing image processing system (https:/ / www.piesat.cn/en/index html) (accessed on 12 October 2020).

Conflicts of Interest: The authors declare no conflict of interest.

\section{Appendix A}

Table A1. Land-use classification using the OOC method.

\begin{tabular}{|c|c|c|c|}
\hline Categories & Land-Use & Introduction & $\begin{array}{l}\text { Assigned Surface } \\
\text { Emissivity [40] }\end{array}$ \\
\hline \multirow{4}{*}{$\begin{array}{l}\text { Blue-green space } \\
\text { (BGS) }\end{array}$} & Water & River, creeks, lakes, and ponds & 0.9925 \\
\hline & Tree & Evergreen trees, deciduous trees, and a mixture of both & 0.95 \\
\hline & Shrub & Forest nurseries, hedges, and ornamental plants & 0.95 \\
\hline & Lawn & Green land, mainly turf & 0.95 \\
\hline
\end{tabular}


Table A1. Cont.

\begin{tabular}{|c|c|c|c|}
\hline Categories & Land-Use & Introduction & $\begin{array}{l}\text { Assigned Surface } \\
\text { Emissivity [40] }\end{array}$ \\
\hline \multirow{9}{*}{$\begin{array}{l}\text { Impervious } \\
\text { surface }\end{array}$} & Plastic runway & Athletic tracks paved with plastic compounds, and so on & 0.92 \\
\hline & Hard-top pavement & Asphalt and concrete pavement & 0.85 \\
\hline & Cement pavement & Traffic road paved with cement mortar & 0.90 \\
\hline & Demolition of open space & $\begin{array}{l}\text { Closed construction site or temporarily vacant land } \\
\text { for demolition }\end{array}$ & 0.83 \\
\hline & Light-weighted steel roof & Light steel roofs, mostly mobile houses or simple houses & 0.66 \\
\hline & Bituminous roof & $\begin{array}{l}\text { Asphalt paper waterproof roofs, more common in low- } \\
\text { and high-density old residential areas }\end{array}$ & 0.85 \\
\hline & Glass curtain wall & Glass exterior wall of high-rises used as office premises & 0.94 \\
\hline & Light-colored wall & $\begin{array}{l}\text { Building walls furnished with light-colored } \\
\text { coating materials }\end{array}$ & 0.90 \\
\hline & Shadow & Shadow of buildings and tall trees & - \\
\hline
\end{tabular}

Table A2. The class-level landscape pattern indices of BGS.

\begin{tabular}{|c|c|c|c|}
\hline Indices and Abbreviation & Unit & Formula & Introduction \\
\hline LPI-Largest Patch Index & $\%$ & $\begin{array}{c}\max _{i=1}^{i} a_{i j} \\
L P I=\frac{A_{i}}{A_{i j}: \text { Patch } i j \text { area; }} \\
A_{i}: \text { Total landscape area }\end{array}$ & Maximum patch percentageLandscape area ratio \\
\hline NP_Number of Patches & - & $\begin{array}{c}N P=n_{i} \\
n_{i}: \text { Total area of category } i \\
\text { landscape elements }\end{array}$ & The number of patches in the study area \\
\hline MPS—Mean Patch Size & ha & $\begin{array}{c}M P S=A_{i} / N P \\
A_{i}: \text { Total landscape area; } \\
N P: \text { number of patches }\end{array}$ & Mean patch size \\
\hline SPLIT—Splitting Index & $\%$ & $\begin{array}{c}S P L I T=\frac{D_{i}}{A_{i}} \\
D_{i}: \text { Distance index of landscape type } i ; \\
A_{i}: \text { Total landscape area }\end{array}$ & Degree of patch dispersion \\
\hline
\end{tabular}

Table A3. Illustrations of seven typical land parcel types with differential land developmental intensity.

\begin{tabular}{ll}
\hline Type & Introduction \\
\hline Type I: Park and recreational landscape & \\
& Park and recreational landscape featured with high \\
vegetation cover $(\geq 60 \%)$ and low impervious cover \\
(ranging between 5 and $20 \%)$.
\end{tabular}


Table A3. Cont.

\begin{tabular}{ll}
\hline Type & Introduction \\
\hline Type II: Mixture of high-density residential and commercial area & \\
\end{tabular}

Type III: Poorly planned old residential areas

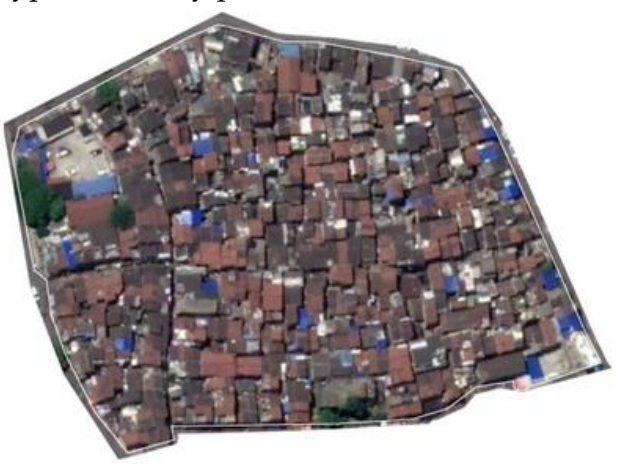

Old residential areas with a construction age of more than 50 years because the overall area has not been properly planned (e.g., in terms of roads, greening, housing). Mainly includes two types, 2-3 high-density old residential areas with a building density of $50-88 \%$ (averaged $61 \%$ ), or single-story bungalows or 3-6 floors of old residential apartments with a building density of $46-66 \%$ (approximately averaged 56\%).

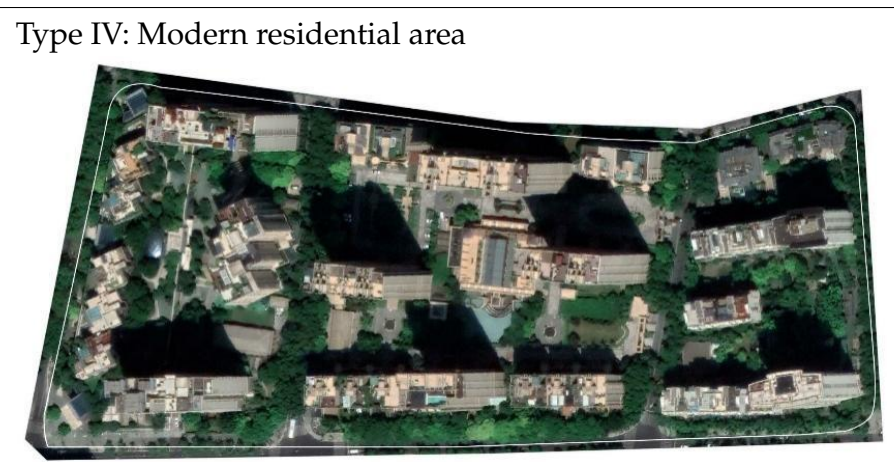

Modern residences with scientific and complete overall planning concepts, large distances between high-rise buildings, high vegetation coverage, and complete public service facilities. The building density varies between 25 and 35\% (approximately averaged 26\%).

Type V: Mixture of land under construction and high-density low-rise

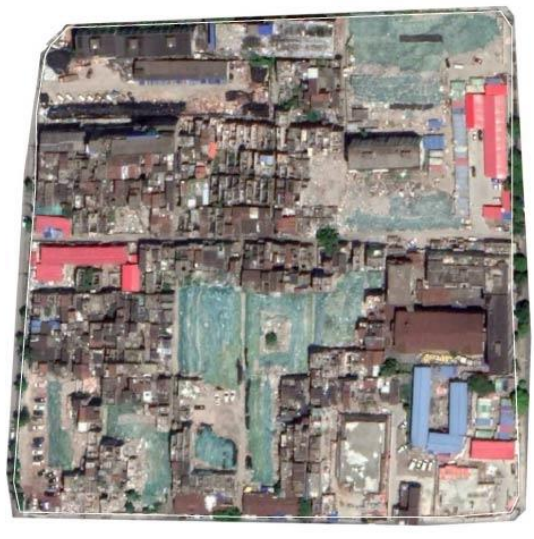

Mixture of urban development land, including land to be demolished for reconstruction, land used for demolition and reconstruction, and land under construction. After the original building is demolished, temporary construction site housing is often built to facilitate construction. 
Table A3. Cont.

Type
Type VI: Mixture of medium-density residential and

Type VII: University campus with high green cover and low- to medium-density buildings

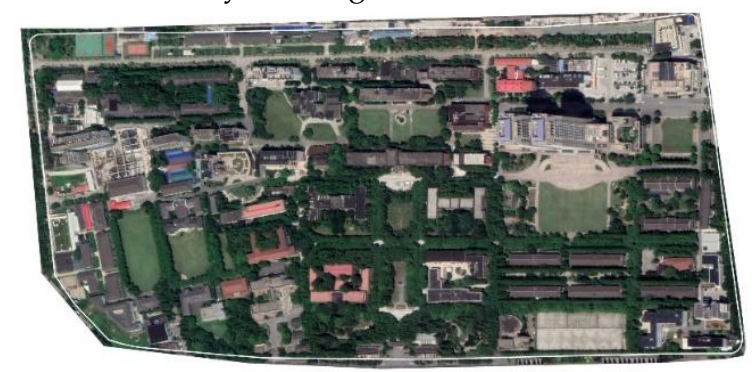

Except for parks, areas with high green coverage, mainly low-rise, multi-story buildings, with building density varying between 15 and $30 \%$.

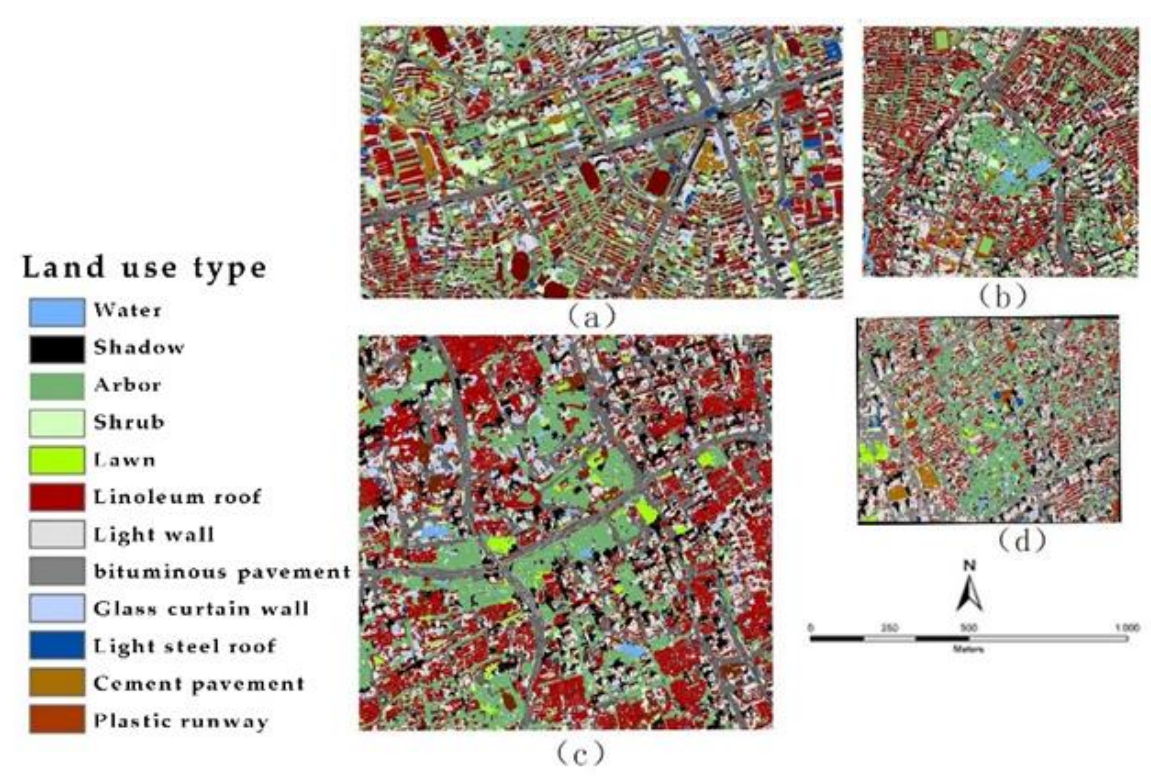

Figure A1. Land-use classification of the four UFZs. (a-d) represent Wujiaochang, Peace Park, Urban Core, and Xujiahui, respectively. 


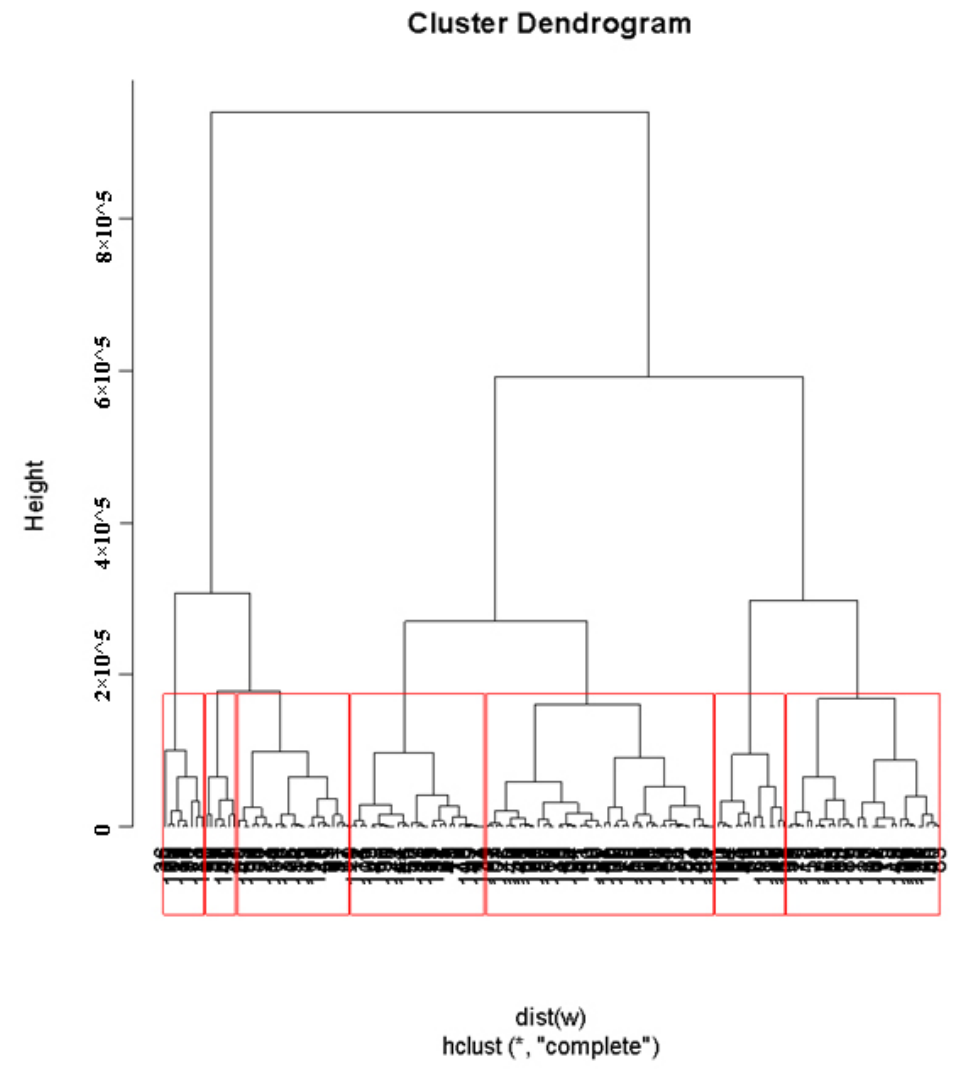

Figure A2. Hierarchical clustering dendrogram showing seven LUF types.

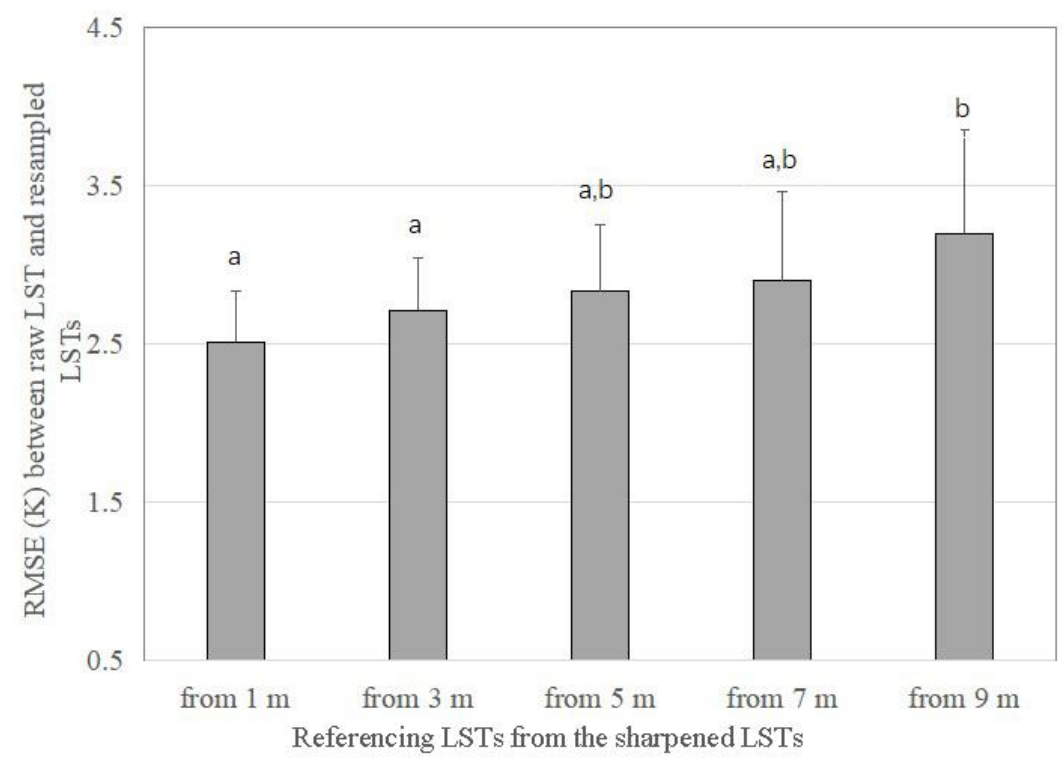

Figure A3. Pairwise RMSEs between the original $30 \mathrm{~m}$ LST and the resampled $30 \mathrm{~m}$ LSTs from the thermally sharpened products (1-9 m). Different symbols $(\mathrm{a} / \mathrm{b})$ indicate significant differences at the 0.05 level.

\section{References}

1. Li, J.-J.; Wang, X.-R.; Wang, X.-J.; Ma, W.-C.; Hao, Z. Remote sensing evaluation of urban heat island and its spatial pattern of the Shanghai metropolitan area, China. Ecol. Complex. 2009, 6, 413-420. [CrossRef]

2. Perz, S.G.; Xia, Y.; Shenkin, A. Global Integration and Local Connectivity: Trans-boundary Highway Paving and Rural-Urban Ties in the Southwestern Amazon. J. Lat. Am. Geogr. 2014, 13, 205-239. [CrossRef] 
3. Wong, P.; Boon-Thong, L.; Leung, M. Hot Spots of Population Growth and Urbanisation in the Asia-Pacific Coastal Region. In Global Change and Integrated Coastal Management; Springer: Dordrecht, The Netherlands, 2006; pp. 163-195.

4. Schneider, A.; Friedl, M.A.; Potere, D. Mapping global urban areas using MODIS 500-m data: New methods and datasets based on 'urban ecoregions'. Remote Sens. Environ. 2010, 114, 1733-1746. [CrossRef]

5. United Nations; DESA. Revision of World Urbanization Prospects; DESE: New York, NY, USA, 2018; Volume 2021.

6. Zhang, H.; Li, T.-T.; Han, J.-J. Quantifying the relationship between land use features and intra-surface urban heat island effect: Study on downtown Shanghai. Appl. Geogr. 2020, 125, 102305. [CrossRef]

7. Shen, L. The Study of the Response Relationship of Land Cover and Its Changes in the City of Low Urban Background. Ph.D. Thesis, Zhejiang University, Hangzhou, China, 2013.

8. Wang, Y.; Bakker, F.; Groot, R.; Wörtche, H. Effect of ecosystem services provided by urban green infrastructure on indoor environment: A literature review. Build. Environ. 2014, 77, 88-100. [CrossRef]

9. Gobster, P.H. Alternative Approaches to Urban Natural Areas Restoration: Integrating Social and Ecological Goals. In Forest Landscape Restoration; USDA: Washington, DC, USA, 2012; pp. 155-176.

10. Wang, Y.; Ni, Z.; Peng, Y.; Xia, B. Local variation of outdoor thermal comfort in different urban green spaces in Guangzhou, a subtropical city in South China. Urban For. Urban Green. 2018, 32, 99-112. [CrossRef]

11. Mallick, J.; Rahman, A.; Singh, C.K. Modeling urban heat islands in heterogeneous land surface and its correlation with impervious surface area by using night-time ASTER satellite data in highly urbanizing city, Delhi-India. Adv. Space Res. 2013, 52, 639-655. [CrossRef]

12. Xiao, J.Y.; Zhang, Q.; Wang, Y.; Na, J.I.; Xing, L.I. Urban Surface Heat Flux Analysis Based on Remote Sensing: A Case Study of Shijiazhuang City. Sci. Geogr. Sin. 2014, 34, 338-343.

13. Stone, B.; Norman, J. Land use planning and surface heat island formation: A parcel-based radiation flux approach. Atmos. Environ. 2006, 40, 3561-3573. [CrossRef]

14. Hove, L.V.; Jacobs, C.; Heusinkveld, B.G.; Elbers, J.A.; Driel, B.V.; Holtslag, A. Temporal and spatial variability of urban heat island and thermal comfort within the Rotterdam agglomeration. Build. Environ. 2015, 83, 91-103. [CrossRef]

15. Chen, H.S.; Li, X.; Wenjian, H. Numerical simulation of the effect of land use change on regional climate in China in recent 20 years. Atmos. Sci. 2015, 2, 357-369.

16. Hua, W.; Haishan, C.; Xing, L. Land use/cover change and its climate effects in China: A review. Adv. Earth Sci. 2014, 9, 1025-1036.

17. Lin, Y.; Jim, C.Y.; Deng, J.; Wang, Z. Urbanization effect on spatiotemporal thermal patterns and changes in Hangzhou (China). Build. Environ. 2018, 145, 166-176. [CrossRef]

18. Weng, Q. Thermal infrared remote sensing for urban climate and environmental studies: Methods, applications, and trends. ISPRS J. Photogramm. Remote Sens. 2009, 64, 335-344. [CrossRef]

19. Bonafoni, S.; Anniballe, R.; Gioli, B.; Toscano, P. Downscaling Landsat Land Surface Temperature over the urban area of Florence. Eur. J. Remote Sens. 2016, 49, 553-569. [CrossRef]

20. Holderness, T.; Barr, S.; Dawson, R.; Hall, J. An evaluation of thermal Earth observation for characterizing urban heatwave event dynamics using the urban heat island intensity metric. Int. J. Remote Sens. 2013, 34, 864-884. [CrossRef]

21. Li, H. Thermal Environment of Medium Cities Supported by Multi-Source Remote Sensing Data. Ph.D. Thesis, Chengdu Univerisity of Technology (CDUT), Chengdu, China, 2012.

22. Bo, D.; Xijin, Z.; Shangming, D.; Qiang, Y. Spatial characteristics and countermeasures of urban thermal environment in Chengdu. Sichuan Environ. 2011, 30, 124-127.

23. Ma, H.; Li, T.; Jiang, Z.H.; Peng, G. Unexpected large-scale atmospheric response to urbanization in East China. Clim. Dyn. 2018, 52, 4293-4303. [CrossRef]

24. Ichinose, T.; Liu, K. Modelling the Relationship between the Urban Development and Subsurface Warming in Seven Asian Megacities. Sustain. Cities Soc. 2018, 38, 560-570. [CrossRef]

25. Doan, V.Q.; Kusaka, H.; Nguyen, T.M. Roles of past, present, and future land use and anthropogenic heat release changes on urban heat island effects in Hanoi, Vietnam: Numerical experiments with a regional climate model. Sustain. Cities Soc. 2019, $47,101479$. [CrossRef]

26. Huang, X. Study on Hyperspectral Image Classification Based on Statistics; UESTC: Chengdu, China, 2008.

27. Li, Y. Street level urban design qualities for walkability: Combining 2D and 3D GIS measures. Comput. Environ. Urban Syst. 2017, 64, 288-296.

28. McGarigal, K.; Cushman, S.; Ene, E. FRAGSTATS: Classification Map Spatial Pattern Analysis Procedures; USDA: Washington, DC, USA, 2012; Volume 2021.

29. Zhou, Y.; Zhou, J. The Urban Eco-environ-mental Estimating System Based on 3-dimension Vegetation Quantity. Chin. Landsc. Archit. 2001, 17, 77-79.

30. USDOI; USGS. Landsat 8 (L8) Data Users Handbook; Version 1.0; EROS: Sioux Falls, SD, USA, 2015.

31. Guo, Y.-J.; Han, J.-J.; Zhao, X.; Dai, X.-Y.; Zhang, H. Understanding the Role of Optimized Land Use/Land Cover Components in Mitigating Summertime Intra-Surface Urban Heat Island Effect: A Study on Downtown Shanghai, China. Energies 2020, 13, 1678. [CrossRef] 
32. Zhang, H.; Jing, X.-M.; Chen, J.-Y.; Li, J.-J.; Schwegler, B. Characterizing Urban Fabric Properties and Their Thermal Effect Using QuickBird Image and Landsat 8 Thermal Infrared (TIR) Data: The Case of Downtown Shanghai, China. Remote Sens. 2016, 8, 541. [CrossRef]

33. Nichol, J.E. High-Resolution Surface Temperature Patterns Related to Urban Morphology in a Tropical City: A Satellite-Based Study. J. Appl. Meteorol. 1996, 35, 135-152. [CrossRef]

34. Weng, Q.; Lu, D.; Schubring, J. Estimation of Land Surface Temperature-Vegetation Abundance Relationship for Urban Heat Island Studies. Remote Sens. Environ. 2004, 89, 467-483. [CrossRef]

35. Jiménez-Muñoz, J.C.; Sobrino, J.A. A generalized single-channel method for retrieving land surface temperature from remote sensing data. J. Geophys. Res. Atmos. 2003, 108, 4688. [CrossRef]

36. He, L.; Yan, G.; Wang, Q.; Li, X. Models and Its Analysis about the Atmospheric Correction of Optical Remote Sensing Imagery. Geo-Inf. Sci. 2005, 7, 33-38.

37. Nurit, A.; William, P.K.; Martha, C.A.; Fuqin, L.; Christopher, M.U.N. A vegetation index based technique for spatial sharpen-ing of thermal imagery. Remote Sens. Environ. 2007, 107, 545-558.

38. Zhang, H.; Li, T.-T.; Liu, Y.; Han, J.-J.; Guo, Y.-J. Understanding the contributions of land parcel features to intra-surface urban heat island intensity and magnitude: A study of downtown Shanghai, China. Land Degrad. Dev. 2020, 32, 1353-1367. [CrossRef]

39. Mevik, B. The pls Package: Principal Component and Partial Least Squares Regression in R. J. Stat. Softw. 2007, 18, 2. [CrossRef]

40. Uni-Trend Inc., version 1.08.14s; Uni-Trend Technology Co., Ltd.: Guangdong, China, 2014. 